Silmara Alessi Guebur Roehrig roehrig@utfpr.edu.br https://orcid.org/0000-0003-3296-7024 Paraná (UTFPR), Curitiba, Paraná, Brasil

Marcos Vinícius Faian Santos marcos faian@hotmail.com https://orcid.org/0000-0002-9119-5389 Universidade Tecnológica Federal do Paraná (UTFPR), Curitiba, Paraná, Brasil

\section{A física nos anos iniciais da educação básica: uma análise dos documentos curriculares adotados pela rede municipal de Curitiba/PR}

\section{RESUMO}

Este artigo apresenta um estudo sobre os conhecimentos físicos presentes em documentos curriculares dos anos iniciais do Ensino Fundamental. O objetivo é abordar a questão da inserção da Física no âmbito do componente curricular referente às Ciências Naturais para esta etapa de ensino, tendo em vista as implicações para a organização didática docente e a formação inicial em Pedagogia. Trata-se de uma pesquisa do tipo documental, em que os documentos a serem analisados correspondem aos textos curriculares adotados pela rede municipal de ensino de Curitiba/PR nas últimas três décadas: o Currículo Básico para a Escola Pública do Estado do Paraná (1990), os Parâmetros Curriculares Nacionais - ensino de primeira à quarta série (1997) e o Currículo do Ensino Fundamental de Curitiba (2016). Para a constituição dos dados que viabilizaram a análise, utilizou-se a metodologia da análise textual discursiva e, a partir do processo de organização das informações, foram construídas as seguintes categorias de análise: 1) conteúdos de Física indicados para as séries iniciais; 2) conhecimentos das Ciências Naturais que remetem à Física, indicados para as séries iniciais e 3) temáticas amplas que podem ser vinculadas a conhecimentos de Física nas séries iniciais. Como resultados, percebeu-se que conhecimentos de Física estão presentes de maneira explicita em todos os documentos analisados, porém com o passar do tempo as orientações curriculares incorporaram vertentes metodológicas em que os conteúdos da Física são cada vez mais articulados com temáticas do ensino de Ciências, bem como temas atuais de caráter científico e tecnológico, e suas relações no contexto social. Estes resultados mostram que a Física constitui-se em uma importante dimensão para a introdução às Ciências da Natureza nas séries inicias, e precisa ser abordada em conjunto com os conhecimentos das demais áreas que pertencem a essa ciência. Isso implica que a formação inicial nos cursos de licenciatura em Pedagogia deve garantir que os futuros professores, que atuarão nos anos iniciais do Ensino Fundamental, tenham acesso a uma formação científica adequada durante a graduação, que permita a articulação da Física, Química e Biologia, sem privilegiar uma área de conhecimento em detrimento de outras, algo que pesquisas apontam ser realidade recorrente nos contextos escolares.

PALAVRAS-CHAVE: Ensino de Ciências. Anos iniciais. Física. Currículo. Ensino Fundamental. 


\section{INTRODUÇÃO}

A presença da Física enquanto disciplina é tradicionalmente associada aos três anos finais da Educação Básica - correspondentes ao Ensino Médio - em que os estudantes se deparam com a divisão das Ciências em suas três principais áreas: Física, Química e Biologia. Neste nível de ensino, pretende-se aprofundar os conhecimentos científicos abordados no âmbito do Ensino Fundamental, tendo em vista as especificidades de cada área de conhecimento enquanto campos de pesquisas científicas.

Embora tal associação faça parte de uma cultura curricular amplamente difundida ao longo da história do ensino de Ciências, a Física não está circunscrita somente no âmbito do currículo do Ensino Médio, mas em todos os níveis educacionais em que a Ciência se faz presente. Enquanto componente das Ciências Naturais, de modo geral, a Física está associada ao estudo das leis que regem os fenômenos da natureza, enquanto a Biologia se preocupa com aspectos associados à vida, e a Química é responsável pelo estudo das transformações da matéria. É importante ressaltar que as três são áreas de conhecimentos complementares entre si, na medida em que cada uma estuda um aspecto particular do mesmo objeto de estudo: a natureza.

A divisão das Ciências no Ensino Médio, aliada à má impressão causada pela maneira como a Física costuma ser abordada neste nível de ensino (com foco em resolução de exercícios matemáticos, pouca abordagem conceitual, falta de contexto) resulta numa formação de sujeitos que concluem a educação básica sem condições de estabelecer relações entre o que foi visto nesta disciplina, e pior, adquirem aversão a esta área. Ao traçar suas metas profissionais após a conclusão da educação básica, os sujeitos que se enquadram neste grupo acabam optando por profissões em que não precisem estudar as ditas "Ciências Exatas", das quais a física é parte integrante. Porém, trata-se de uma perspectiva equivocada, já que grande parte das profissões envolve, de alguma maneira, conhecimentos científicos, que acabam sendo suprimidos em função desta visão distorcida sobre o que de fato ela significa.

Para nos aproximarmos do assunto que pretendemos discutir neste trabalho, abordaremos o caso da formação inicial de professores, em especial a formação em Pedagogia, que permite que o profissional com tal título atue como docente das séries iniciais do Ensino Fundamental. Estudantes e futuros profissionais de Pedagogia passam por uma formação em que se toma contato com diversos conhecimentos tanto do âmbito pedagógico, quanto dos conteúdos específicos que estão previstos nos currículos das séries inicias, como Língua Portuguesa, Matemática, Artes, Ciências, entre outros. Há, contudo, evidências de que algumas áreas são privilegiadas pelos professores em sua atuação profissional, em detrimento de outras, em virtude de problemas com a formação inicial do docente em relação a certas áreas.

Diversos estudos evidenciam que a educação científica nas séries iniciais, desde sua constituição como componente curricular, vem passando por dificuldades e desafios no que condiz aos processos de ensino e aprendizagem (CAMPOS; CAMPOS, 2016). Nesse contexto, somado às questões expostas anteriormente, conceitos da Física a serem abordados nas séries iniciais se apresentam à margem da educação científica, tendo em vista a tendência de 
serem desconsiderados, esquecidos ou deliberadamente evitados pelos docentes (RODRIGUES; TEIXEIRA, 2011; CARVALHO, 1997).

A partir destas considerações, propomos a seguinte pergunta de pesquisa: de que maneira os conhecimentos, conceitos ou conteúdos da Física estão presentes em documentos curriculares no âmbito do ensino de Ciências para as séries inicias? Investigar o currículo pode auxiliar na compreensão do que se espera de docentes atuantes neste nível de ensino, com relação ao ensino de conceitos científicos que levem em conta os componentes curriculares que fazem parte desta área de conhecimento.

Para responder a esta pergunta, foi escolhido o contexto curricular da rede municipal de ensino de Curitiba/PR, tomando como objetos de estudo três documentos curriculares vigentes no período correspondente aos últimos trinta anos. O objetivo do trabalho é analisar como a Física é abordada em cada documento, levando em conta o contexto histórico em que o texto curricular foi escrito. Com isso, pretende-se levantar considerações sobre a evolução histórica da presença da Física no currículo das séries iniciais, as possibilidades didáticas e pedagógicas que estes documentos apresentam aos docentes, bem como potenciais elementos para promover o fortalecimento da formação científica de futuros professores nos cursos de Pedagogia.

\section{APONTAMENTOS SOBRE O ENSINO DE CIÊNCIAS NAS SÉRIES INICIAIS}

A complexidade que permeia as discussões sobre os processos de ensino e aprendizagem dos conhecimentos científicos nos anos iniciais da educação básica não pode ser desconsiderada do ponto de vista de uma pesquisa sobre currículo. Embora a dimensão curricular seja um importante elemento para um ensino condizente com o contexto social e histórico dos estudantes, por si só não garante que a prática docente seja efetiva dentro do que se espera de acordo com os documentos curriculares.

Pesquisas apontam que um dos aspectos relevantes, relacionado aos problemas do ensino de Ciências para as séries iniciais, diz respeito às deficiências na formação científica dos docentes responsáveis por esta etapa da educação. Campos e Campos (2016), por exemplo, apontam estudos que destacam como principais desafios envolvidos na formação de pedagogos e pedagogas, para a abordagem das ciências naturais nesta etapa do ensino,

1. A formação específica que visa o ensino de Ciências Naturais corresponde, geralmente, a uma pequena parte da carga horária do curso e não garantem formação completa no ensino em questão.

2. Ausência ou inadequação dos espaços físicos como laboratórios e bibliotecas;

3. Falta de preparo de pessoas especializadas no assunto [Ciências nos anos iniciais] capaz de oferecer respaldo na elaboração dos planejamentos e treinamento dos docentes. (CAMPOS; CAMPOS, 2016, p. 139).

Dentre estes desafios, talvez o mais importante seja a deficiência na formação inicial de professores, em que as Ciências da Natureza não são adequadamente abordadas, deixando uma lacuna que irá repercutir na atividade 
deste profissional. Sem a formação adequada, a tendência é que profissionais docentes recorram a alternativas de sobrevivência, que podem levar a omissão de certos conhecimentos em detrimento daqueles em que não se sente seguro em abordar. As autoras destacam um estudo em que se verificou que o papel do professor de Ciências por parte de estudantes de Pedagogia costuma ser secundarizado, na medida em que "não parece estar entre as intenções formativas explicitas levar o futuro professor dos anos iniciais à compreensão dos objetivos de Ciências para esta etapa de ensino" (idem).

Com relação às áreas de conhecimento que fazem parte do ensino de Ciências no nível fundamental, destacam-se as Ciências Físicas (Física, Química, Geologia e Astronomia) e as Ciências Biológicas (Biologia, Botânica e Zoologia), no que condiz aos conteúdos específicos (MAGALHÃES; PIETROCOLA, 2005). Tais demandas, presentes nos Parâmetros Curriculares Nacionais (PCN), implicam numa formação inicial em que o profissional tenha condições de abordar conceitos elementares de todas estas áreas, a fim de proporcionar a socialização dos conhecimentos científicos, bem como seus processos e métodos, mesmo que em uma perspectiva introdutória. Sendo assim, tanto docentes que atuam nas séries iniciais, em geral formados em Pedagogia, quanto os que atuam nas séries finais, precisam ter conhecimentos de conteúdos e métodos condizentes com todas as demandas da educação científica.

Tendo em vista os aspectos acima abordados, aponta-se uma questão bastante contundente: a formação inicial em cursos de Pedagogia que incluem o ensino de Ciências proporciona de fato a formação para que futuros professores desenvolvam os saberes científicos necessários para sua atuação nas séries iniciais? Esta questão é fundamental para a discussão sobre o currículo, uma vez que os futuros professores só poderão garantir o ensino dos conhecimentos científicos dispostos nos documentos se tiverem passado por uma formação condizente.

No que condiz à realidade observada nas salas de aula, Rodrigues e Teixeira (2011) apontam estudos que mostram haver

\footnotetext{
evidências que a disciplina Ciências é pouco vivenciada em sala de aula nas séries iniciais do ensino fundamental e geralmente, quando estas acontecem, são duas aulas por semana, com ênfase em biologia, deixando de lado as outras áreas das ciências (p. 4401-4402).
}

Isso significa que algumas áreas das Ciências Naturais são mais privilegiadas do que outras, em função da formação e do preparo do profissional pedagogo que está à frente da classe. No que condiz ao ensino de Física neste contexto, Rodrigues e Teixeira destacam pesquisas que evidenciam a falta de motivação de docentes pedagogos ou pedagogas em "ensinar os diversos conteúdos de física por sentirem-se inseguros devido à falta de conhecimento do conteúdo científico" (idem), além da existência da crença de que tais conhecimentos sejam inacessíveis para crianças, por serem excessivamente complexos.

A implementação efetiva do ensino das Ciências nos anos iniciais, com destaque para o ensino de Física, vem sendo orientada por diversos pesquisadores da área, conforme apontam Mozena e Ostermann (2008). Carvalho (1997) já destacava as possibilidades de promover a abordagem da Física nas séries iniciais, levando em conta elementos essenciais para o processo 
de ensino e aprendizagem, como o papel do conteúdo, dos conceitos espontâneos, das questões e da construção social, mostrando caminhos possíveis para a estruturação de atividades sobre o conhecimento físico neste contexto.

Contudo, apesar deste movimento no campo das pesquisas se mostrar em ascensão, esbarra-se com o problema da falta de preparo de professores formados em Pedagogia para a consolidação do ensino de Física nos primeiros anos do Ensino Fundamental. Rodrigues e Teixeira (2011) apresentam resultados de uma pesquisa com docentes das séries iniciais, em que a maior parte dos sujeitos alega não trabalhar conhecimentos da Física com suas turmas. De acordo com os autores,

\footnotetext{
Nas respostas negativas a maioria das justificativas era que não gostava [da física] pois 'tinha muitos cálculos', ou 'não teve bons professores' ou 'não foi visto no curso' ou mesmo porque 'é muito difícil'. Outras justificativas também chamam a nossa atenção: 'não tem aplicação em sala de aula', 'não dá para contextualizar'. Estas últimas justificativas nos parece sinalizar limitações teóricas na preparação que os docentes têm nesta área. (p. 44014406).
}

De modo geral, buscamos até aqui destacar algumas questões que permeiam o problema do ensino de Física no Ensino Fundamental I. Certamente inúmeros outros tópicos relacionados ao tema, que não foram abordados aqui, mereceriam destaque; porém, o objetivo dessa pesquisa é compreender como os documentos curriculares referentes ao ensino de Ciências - em especial da Física das séries inicias se constituíram ao longo do tempo, especialmente aqueles utilizados na rede municipal de ensino da cidade de Curitiba/PR.

\section{DOCUMENTOS CURRICULARES DE CIÊNCIAS PARA AS SÉRIES INICIAIS}

Desde que se iniciaram os estudos sobre currículo, cerca de um século atrás, muito se tem discutido acerca das características e particularidades desta dimensão do âmbito educacional. Com relação às teorias de currículo, Silva (2010) aponta três grandes vertentes: a tradicional, a crítica e a pós-crítica. De acordo com o autor, a primeira se objetiva na transmissão de conteúdos específicos de cada área do conhecimento, com foco em ensino, aprendizagem, avaliação, metodologia, organização, planejamento, eficiência e objetivos. Já as teorias críticas se caracterizam pela presença de concepções que levam em conta ideologia, reprodução cultural, poder, classe social, capitalismo, resistência, conscientização, libertação e emancipação, relações sociais de produção e currículo oculto. As teorias pós-críticas levam em conta identidade, alteridade, subjetividade, significação e discurso, saber-poder, representação, cultura, gênero, raça, etnia, sexualidade e multiculturalismo.

Estas vertentes, de acordo com Silva (2010), se materializam em forma de discursos curriculares em que, no fundo, o que se busca é definir quais conhecimentos devem ser ensinados. Ou seja, busca estabelecer quais conhecimentos devem ser aprendidos pelos estudantes dos mais diversos níveis de ensino, dentro de uma concepção de formação considerada adequada de acordo com cada contexto social, histórico, político, econômico e cultural (GESSER, 2002). Reconhecemos a complexidade inerente ao debate sobre currículo, porém buscaremos focar em alguns elementos que repercutem em 
certas políticas curriculares mais recentes, especialmente na construção de documentos norteadores para o contexto estudado neste trabalho.

No que tange os estudos em ensino de Ciências e o campo do currículo, Lopes e Macedo (2004) apontam a pouca ênfase em discussões sobre questões históricas, políticas e culturais. Para as autoras, "os estudos em currículos de ciências [...] ainda tem se voltado preferencialmente para proposições curriculares que privilegiam novas abordagens metodológicas" (p. 9), fato que contribui no sentido de desconsiderar a educação "como campo de produção cultural, portanto intrinsecamente político e social".

Os fatores que vieram a influenciar historicamente as decisões sobre o currículo de Ciências são abordados por Chassot (2004), que evidencia a influência de eventos históricos decorrentes da Segunda Guerra Mundial e da posterior Guerra Fria, elencando suas consequências para o ensino de Ciências no mundo. Nesse contexto, surgiram no Brasil propostas de inovações curriculares para o ensino de Ciências, desenvolvidas com base em projetos estadunidenses de educação científica, cuja influência se faz presente nos dias atuais no âmbito das decisões curriculares.

A partir de tais influências, temos hoje um conjunto de conhecimentos estabelecidos pela área como importantes para o âmbito da educação básica, desde o Ensino Fundamental I até o Ensino Médio. As políticas curriculares dos diversos períodos buscaram promover adequações nos currículos de acordo com o contexto social e o momento histórico. No que se refere ao currículo para as séries iniciais no município de Curitiba, que consiste no contexto analisado neste trabalho, faremos alguns apontamentos sobre os referenciais adotados nos últimos trinta anos.

Após o final do período da ditadura militar, ocorrido em meados da década de 1980, iniciou-se o processo de construção do Currículo Básico do Estado do Paraná, que foi publicado no ano de 1990, com orientações para todas as séries do antigo ensino de primeiro grau, desde a pré-escola até a oitava série. Este documento, escrito em conjunto por educadores da rede estadual de ensino, se apresenta fundamentado na pedagogia histórico-crítica proposta por Demerval Saviani, em termos de orientações pedagógicas mais amplas, e para cada disciplina são elencados conteúdos que devem ser abordados em cada etapa do nível fundamental de ensino.

Este foi o documento vigente nos estabelecimentos de ensino no contexto paranaense, pelo menos até o ano de 1996, com a publicação dos Parâmetros Curriculares Nacionais (PCN). Com a publicação do referido documento, ocorreram mudanças importantes no cenário da educação básica, incluindo a mudança da nomenclatura dos níveis de ensino - Ensino de Primeiro Grau passa a se chamar Ensino Fundamental - e a proposta de abordagem por temas estruturantes, ao invés de conteúdos específicos. No ano de 1997, são publicados os cadernos dos parâmetros para o ciclo da 1a a a a série em dez volumes, sendo seis deles referentes às disciplinas (Língua Portuguesa, Matemática, Ciências Naturais, História e Geografia, Arte, Educação Física) e os demais à abordagem de temáticas mais amplas (Apresentação dos Temas Transversais e Ética, Meio Ambiente e Saúde, Pluralidade Cultural e Orientação Sexual). pelas mais diversas instâncias da educação, desde a formação de professores até 
a produção de materiais didáticos. Cada estado ou município poderia adotar este referencial, ou construir o seu próprio documento. No Paraná, a partir de 2003, a rede estadual optou por escrever suas próprias diretrizes curriculares para os anos finais do ensino fundamental e para o ensino médio, enquanto a rede municipal de Curitiba adotou os parâmetros por um período de quase vinte anos, até a publicação de seus referenciais próprios no ano de 2016.

O quadro 01 apresentado a seguir relaciona as diferentes nomenclaturas das etapas do Ensino Fundamental utilizadas no período que compreende a pesquisa.

Quadro 1 - nomenclaturas adotadas nos diferentes momentos históricos

\begin{tabular}{|c|c|c|}
\hline Década de 1980/90 & Década de 1990/2000 & Década de 2010 \\
\hline Ensino de Primeiro Grau & Ensino Fundamental & Ensino Fundamental \\
\hline $\begin{array}{l}\text { Ciclo Básico de } \\
\text { Alfabetização } \\
\text { (1a e 2a séries) }\end{array}$ & $\begin{array}{l}\text { Primeiro Ciclo } \\
\text { (1aㅡ e } 2^{a} \text { séries) }\end{array}$ & $\begin{array}{c}\text { Ciclo I } \\
(1 \circ, 2 \circ \text { e } 3 \circ \text { anos })\end{array}$ \\
\hline 3a e 4aa séries & $\begin{array}{l}\text { Segundo Ciclo } \\
\text { (3a e 4a séries) }\end{array}$ & $\begin{array}{c}\text { Ciclo II } \\
\text { (4ㅇe e 5ㅇanos) }\end{array}$ \\
\hline 5a a 8a série & $\begin{array}{l}\text { Terceiro Ciclo (5a e 6a séries) } \\
\text { Quarto Ciclo (7ạ e 8a séries) }\end{array}$ & $\begin{array}{l}\text { Ciclo III (6ㅇ e 7ㅇ anos) } \\
\text { Ciclo IV (8 e 9o anos) }\end{array}$ \\
\hline
\end{tabular}

Fonte: Autoria própria (2019).

O currículo para o Ensino Fundamental da rede municipal de Curitiba, organizado no formato de plano curricular, está disposto em forma de tabelas com objetivos para cada ano do Ensino Fundamental, e também na forma de cadernos por disciplinas. O quarto volume corresponde ao Caderno de Ciências, apresentando os objetivos para as séries dos ciclos I, II, III e IV (CURITIBA, 2016). Neste documento, afirma-se que a principal finalidade do ensino de ciências é

\begin{abstract}
proporcionar aos(às) estudantes a alfabetização científica na perspectiva do letramento, utilizando o conhecimento científico como ferramenta de leitura de mundo, a fim de que compreendam a natureza da Ciência e a influência dos avanços científicos e tecnológicos na sociedade; entendam as questões culturais, sociais, éticas e ambientais, associadas ao uso dos recursos naturais; e possam pensar e agir de modo informado perante os desafios da contemporaneidade. (CURITIBA, 2016, p. 5).
\end{abstract}

Uma vez que estes documentos curriculares se constituem objetos de análise deste estudo, pretendemos investigar como os conceitos específicos da Física estão presentes no conteúdo destes documentos.

\title{
METODOLOGIA
}

Este artigo resulta de uma pesquisa realizada no contexto do curso de Licenciatura em Física de uma universidade pública localizada em Curitiba/PR, o qual justifica a seleção dos documentos curriculares adotados pelos docentes dos anos iniciais no âmbito deste município. Consiste numa pesquisa de natureza qualitativa, do tipo documental, sendo os objetos de análise constituídos pelos documentos curriculares adotados pela rede municipal de Curitiba no período referente aos últimos trinta anos. De acordo com Sá-Silva, Almeida e Guindani (2009, p. 05) "a pesquisa documental é um procedimento que se utiliza de métodos e técnicas para a apreensão, compreensão e análise de documentos dos 
mais variados tipos", sendo importante levar em conta o contexto histórico em que o documento foi escrito, quem esteve envolvido na produção dos textos e a garantia da veracidade do documento.

Tendo em vista tais aspectos, foram selecionados os documentos curriculares que foram utilizados pelos docentes dos anos iniciais do Ensino Fundamental em Curitiba, adotados no período compreendido entre 1990 e 2018. Serão três currículos vigentes nesse período a serem analisados: o Currículo Básico do Estado do Paraná (PARANÁ, 1990), Parâmetros Curriculares Nacionais - Ciências Naturais 1ạ a 4ạ séries (BRASIL, 1997) e o Currículo do Ensino Fundamental - Ciências (CURITIBA, 2016). A atual Base Nacional Comum Curricular não será analisada neste trabalho por se encontrar ainda em processo de implementação.

Quanto à metodologia de análise, será utilizada a Análise Textual Discursiva (MORAES; GALIAZZI, 2011). A fim de compreender como a física vem sendo abordada em documentos curriculares que guiaram a atividade dos docentes dos anos iniciais nas últimas três décadas, organizou-se a análise tendo em vista as etapas propostas nesta perspectiva, que consistem em: 1) desmontagem dos textos, que corresponde ao processo também conhecido como unitariação; 2) estabelecimento de relações, em que as unidades obtidas anteriormente são organizadas em categorias de análise; 3) captando o novo emergente, em que o esforço da análise das categorias proporciona uma nova compreensão sobre o objeto de estudo e 4) auto-organização, em que se podem vislumbrar os resultados do trabalho de análise a serem comunicados em forma de textos analíticos.

Para as duas primeiras etapas desta pesquisa, a leitura integral do corpus referente aos três documentos analisados permitiu a separação das unidades de análise, que levaram à construção das categorias que serão aqui discutidas.

Tendo em vista o objetivo deste trabalho, iremos destacar três categorias, acerca do conteúdo dos documentos curriculares analisados: 1) conteúdos de Física indicados para as séries iniciais; 2) conhecimentos das Ciências Naturais que remetem à Física indicados para as séries iniciais e 3) temáticas amplas que podem ser vinculados a conhecimentos de Física nas séries iniciais. Outras unidades de análise que levaram a outras categorias emergentes não serão abordadas neste trabalho em função do recorte escolhido, mas serão discutidas futuramente em outros espaços. As quartas e quintas etapas da análise serão estabelecidas a partir da discussão das categorias, em que serão apresentadas as novas compreensões sobre a presença da física nos documentos curriculares analisados.

\section{DISCUSSÃO DOS RESULTADOS}

Para a discussão e análise dos dados, destacamos cada uma das categorias tendo em vista o modo como a Física se constitui em cada um dos documentos analisados.

1. Conteúdos de Física indicados para as séries iniciais: para esta categoria será discutido de que modo os conteúdos de Física, propriamente ditos, são abordados nos documentos curriculares para as séries iniciais. 
Constituem-se em termos que são tradicionalmente utilizados no âmbito da Física enquanto campo de conhecimento, tendo em vista as grandes temáticas constituídas pela área, a saber: Mecânica, Termodinâmica e Eletromagnetismo.

No Currículo Básico do Estado do Paraná (1990), há indicação explicita de conteúdos da Física para o que na época era chamado de pré-escola e o ciclo básico de alfabetização. Após caracterizar as ciências da natureza tendo em vista a sua relevância na sociedade, a presença no cotidiano e aplicações tecnológicas, o documento apresenta uma lista de conteúdos das Ciências que devem ser abordados em cada etapa. Dentre os conteúdos, destacam-se: luz; calor e suas fontes; noções de movimento e referencial; noções de gravidade; tipos de energia e noções de radiação eletromagnética (infravermelho e ultravioleta). Estes conteúdos aparecem distribuídos entre os cinco anos que compreendem a pré-escola e a antiga quarta série do ensino básico.

Já nos Parâmetros Curriculares Nacionais, especificamente no volume dedicado às Ciências Naturais (BRASIL, 1997), percebe-se a inserção de novas perspectivas metodológicas, como o enfoque Ciência, Tecnologia e Sociedade (CTS), com destaque para as relações entre as Ciências Naturais e tecnologia, tendo em vista a formação para a cidadania desde as séries iniciais. Segundo o documento,

\footnotetext{
Faz-se necessária a discussão das implicações políticas e sociais da produção e aplicação dos conhecimentos científicos e tecnológicos, tanto em âmbito social como nas salas de aula. No campo do ensino de Ciências Naturais as discussões travadas em torno dessas questões iniciaram a configuração de uma tendência do ensino, conhecida como "Ciência, Tecnologia e Sociedade" (CTS), que tomou vulto nos anos 80 e é importante até os dias de hoje. (BRASIL, 1997, p. 20).
}

Em termos de conteúdos de Ciências, "são quatro os blocos temáticos propostos para o ensino fundamental: Ambiente; Ser humano e saúde; Recursos tecnológicos; e Terra e Universo" (BRASIL, 1997, p. 34). Com relação à presença de conteúdos de Física, luz e calor são mencionados dentro da temática Ambiente. A energia é amplamente abordada na temática "Recursos tecnológicos", no que diz respeito ao seu consumo, suas fontes e tipos, aplicações, entre outros. Na temática "Ser humano e saúde" não se apresentam conteúdos de Física explicitamente. Além disso, o tema "Terra e Universo" somente é abordado, neste documento, no espaço destinado aos conteúdos das séries finais do Ensino Fundamental.

O documento curricular do município de Curitiba (2016) apresenta uma perspectiva pedagógica com maior nível de articulação entre metodologias, conhecimentos e temas sociais contemporâneos. Não só apresenta a vertente Ciência, Tecnologia, Sociedade e Ambiente (CTSA) como fundamento da organização do currículo, como estabelece relações interdisciplinares que irão permitir o docente a de fato trabalhar sob esta perspectiva. A organização geral se dá por conteúdos e por ano dos ciclos I e II. Com relação aos conteúdos de Física, há menção explicita sobre a luz (fontes naturais e artificiais), conceitos básicos de ótica (interação da luz com objetos), som (fontes naturais e artificiais), calor (fontes, condutores e isolantes), movimentos de rotação e translação da Terra, noções de gravidade e aspectos de história da física (contribuições de 
Copérnico e Galileu). É importante destacar que a energia é abordada amplamente, porém isso ocorre dentro de temáticas de cunho social, o que iremos destacar na discussão da terceira categoria.

2. Conhecimentos das Ciências Naturais que remetem à Física, indicados para as séries iniciais: nesta categoria, iremos discutir temas que, embora não sejam diretamente associados à Física da maneira como esta vem sendo tradicionalmente constituída, apresentam potencial de inserção dos conhecimentos físicos para a melhor compreensão dos fenômenos naturais estudados.

Em Paraná (1990), destaca-se a presença de conteúdos de Astronomia desde a pré-escola, com a abordagem do movimento e posição da Terra em relação ao Sol e no sistema solar, bem como satélites, planetas e estrelas, efeito da radiação solar na Terra, entre outros. Conteúdos que remetem à Física, apesar de geralmente serem abordados apenas na perspectiva da Biologia, estão também presentes neste documento. Por exemplo: ciclo da água; formação de ventos; impactos do sol na saúde humana e no ecossistema, são assuntos que envolvem conceitos da Física para sua completa compreensão, mas que podem acabar sendo abordados somente do ponto de vista da Biologia. Para dar um exemplo, ao abordar a formação dos ventos, pode-se focar na definição do que é vento, na sua importância para o clima e os ecossistemas, e deixar de lado os processos físicos associados à formação dos ventos (pressão atmosférica, distribuição da radiação solar, processos de transferência de calor, entre outros).

Nos PCN (BRASIL, 1997), além de se destacar o ensino de conceitos associados ao ciclo da água, indica-se a abordagem de relações entre matéria e energia no que diz respeito às transformações que ocorrem no meio ambiente. As transformações que ocorrem no corpo humano, relacionadas à alimentação e todos os seus aspectos, também estão dentre os objetivos de ensino neste documento, e a compreensão dos aspectos físicos das transformações que envolvem calor e energia constituem-se em elementos essenciais para o ensino deste assunto.

O texto curricular de Curitiba (2016, p. 16) apresenta, por exemplo, como um dos objetivos, investigar por meio dos sentidos "propriedades específicas dos materiais: cor, brilho, odor, sabor, textura, transparência, temperatura e forma". Além disso, propõe identificar hábitos que contribuem para a manutenção da saúde dos olhos e dos ouvidos, abordando, por exemplo, o uso de óculos e fones de ouvidos. Em outro momento, destaca "reconhecer que o Sol é fonte de luz e calor para o planeta Terra e afeta os seres vivos, o ar, a água e o solo" (p. 22). Assim como nos PCN, aborda o papel do Sol na saúde humana, com destaque para efeitos da radiação solar na pele. Também é contemplado o ciclo da água e elementos da astronomia, como nos demais documentos. Tais assuntos podem ganhar maior profundidade nas séries iniciais, se o docente tiver conhecimentos de Física e souber como articula-los no processo de ensino.

3. Temáticas amplas que podem ser vinculadas a conhecimentos de Física nas séries iniciais: pretende-se apontar como temas ou questões atuais que envolvem o conhecimento científico são abordados nos documentos analisados. Neste sentido, podemos destacar momentos em que os textos curriculares se referem a temas sociais de cunho científico, como por exemplo, a presença das tecnologias e seus impactos na sociedade. 
No Currículo Básico (PARANÁ, 1990) há poucas referências a temas desta natureza. Há algumas menções, no tópico destinado aos encaminhamentos metodológicos, acerca do papel de alguns avanços científicos e tecnológicos, a fim de justificar o ensino de astronomia; afirma-se que

O avanço científico-tecnológico e o descompasso existente entre este e o
ensino de ciências são notórios. Surge daí a necessidade de enfocar as
questões de astronomia, relacionadas às conquistas tecnológicas
contemporâneas, uma vez que o homem faz parte desse momento histórico
e suas condições de vida, dependem direta ou indiretamente deste
conhecimento. (PARANÁ, 1990, p. 113).

Apesar de ressaltar a relevância destes aspectos na sociedade, tais orientações são apresentadas a título de justificativa do porque ensinar certos conteúdos. Não fica, portanto, claro como o professor irá trabalhar, já que na sessão destinada aos conteúdos, somente aparecem tópicos a serem abordados, conforme discutido na primeira categoria. Percebe-se que não há articulação entre conteúdos da lista e temas desta natureza, cabendo ao docente estabelecêlas de alguma maneira.

Já nos PCN, tendo em vista que a própria organização dos conhecimentos ocorre a partir de temas estruturantes, percebe-se a abordagem de questões associadas aos impactos de algumas atividades humanas relacionadas à ciência e à tecnologia. Destaca-se, no bloco temático "Recursos tecnológicos", a proposta de trabalhar com: Água, lixo, solo e saneamento básico; Captação e armazenamento da água; Destino das águas servidas; Coleta e tratamento de lixo; Solo e atividades humanas; Poluição; Diversidade dos equipamentos.

Para abordar a questão da poluição, por exemplo, defende-se que são necessários "conhecimentos da Biologia, da Física e da Química" (BRASIL, 1997, p. 70). As transformações de energia que ocorrem nos diversos equipamentos tecnológicos também são contemplados. "É o caso de equipamentos que servem à iluminação e à comunicação. Por diferentes que sejam as fontes energéticas, equipamentos de iluminação irão transformá-las em luz (outra forma de energia)" (BRASIL, 1997, p. 71).

O plano curricular da rede municipal de Curitiba apresenta, como conteúdos, algumas temáticas que relacionam a priori conhecimentos da física. Para o primeiro ano, por exemplo, destaca-se como conteúdo "Tecnologias e inovações científicas destinadas às pessoas com defiCiência(s) [sic]: cadeiras de rodas, bengalas, próteses, óculos e aparelhos de surdez" (CURITIBA, 2016, p. 14). É possível associar conceitos físicos a esta temática, associados à visão, audição, ótica, som e a própria mecânica de modo geral. Para o segundo ano, propõe-se, entre outros conteúdos, abordar "Tecnologias criadas pelo ser humano para minimizar os impactos ambientais" (idem, p. 18), cujo objetivo é discutir tecnologias que buscam contribuir para reduzir os impactos de determinada atividades humanas, como filtros em chaminés, catalizadores, reciclagem, produção de energia elétrica a partir da energia solar, entre outros. Para o terceiro ano, propõe-se um aprofundamento da abordagem das tecnologias já estudadas (utilizadas na correção de problemas de visão e audição, por exemplo) e para o quarto ano é indicada a abordagem de aspectos de astronomia e astronáutica, especialmente associados às tecnologias de sondas e foguetes. Por fim, destaca-se como um dos conteúdos o estudo do efeito estufa e o 
aquecimento global, a fim de reconhecer "os impactos da ação humana na atmosfera (por exemplo: a emissão de poluentes, ocasionando o aquecimento global e a destruição da camada de ozônio)" (idem, p. 34).

Tendo em vista os aspectos observados a partir da análise dos documentos curriculares, objetos deste estudo, percebe-se que houve uma crescente articulação de assuntos que relacionam a Física no ensino de Ciências nos anos iniciais do Ensino Fundamental. No currículo básico (PARANÁ, 1990) conteúdos de Física, como ênfase em suas relações com a astronomia, são destacados como conteúdos a serem abordados nas séries do primeiro e do segundo ciclo. Contudo, mesmo que nessa época os conteúdos se apresentassem desarticulados em relação aos demais conhecimentos científicos, o que pode ser interpretado como consequência da tradição curricular baseada em listas de conteúdos específicos, é válido ressaltar que no dado momento histórico, a Física já era explicitamente contemplada no currículo de Ciências para as séries iniciais do Ensino Fundamental no contexto estudado.

Os PCN para esta etapa de ensino (BRASIL, 1997) apresenta uma estrutura diferente de organização curricular, na medida em que define temas estruturantes, em sua maioria de cunho social e tecnológico, ao invés de focar em conteúdos específicos de cada uma das áreas. Nesse sentido, a Física ganha destaque em certos temas, como aqueles relacionados aos impactos das tecnologias na sociedade e no ambiente. Ou seja, de acordo com os PCN, a abordagem da Física nas séries iniciais se faz essencial para o planejamento de um ensino de Ciências que vise promover a compreensão de temas atuais relevantes para a sociedade.

No que diz respeito às orientações curriculares do município de Curitiba (2016), o ensino de Ciências é estruturado de modo a levar em conta a alfabetização científica e tecnológica dos estudantes dos anos iniciais. Na medida em que se assume tal perspectiva, a educação científica precisa apresentar elementos que de fato propiciem a articulação de conceitos científicos e suas implicações na sociedade, aspecto com o qual o documento curricular em questão se apresenta coerente. Tal afirmação se fundamenta na análise, em que foi possível observar que dentre os conteúdos a serem abordados no ensino de Ciências nos anos inicias, a Física está presente para contribuir tanto com a compreensão da temática de cunho social e tecnológico proposta, quanto para o desenvolvimento de relações destes âmbitos com questões relevantes para o estudante enquanto cidadão em processo de formação, com a abordagem de tópicos associados à inclusão e diversidade.

Após a análise empreendida neste trabalho de pesquisa, pudemos construir as compreensões expostas a partir da discussão das categorias. Na perspectiva dos autores, pode-se ainda destacar como os documentos curriculares são marcados pelo seu contexto histórico, bem como pelas diversas vertentes metodológicos para o ensino de Ciências, que ganham ou perdem força nos diferentes períodos históricos. Por exemplo, o Currículo Básico, construído após o fim da ditadura militar, aponta elementos coerentes com currículos fundamentados na teoria crítica, que corroboram com o discurso presente na esfera educacional neste contexto. Apesar disso, mesmo defendendo um ensino em que se leve em conta os conhecimentos e suas relações com a sociedade, 
acaba focando na transmissão de conteúdos, numa perspectiva que se aproxima dos currículos tradicionais.

O contexto histórico em que os PCN foram escritos corresponde ao momento em que ocorre a abertura dos mercados, início das privatizações, implementação do plano real, entre outros fenômenos do contexto econômico que influenciaram as políticas públicas na área da educação, levando em conta o fortalecimento da economia neoliberal no Brasil. No documento curricular, percebe-se maior articulação entre conteúdos de cada disciplina e temáticas de cunho social, apresentando dentre as possibilidades metodológicas a educação com enfoque CTS. Porém, ainda não oferece subsídios de como estabelecer tais articulações, ficando apenas a título de indicação. Este problema parece ser minimizado no documento mais recente, analisado neste trabalho, que já articula conteúdos com temáticas sociais e tecnológicas de cunho científico de maneira a dar mais elementos para os professores organizarem sua atividade docente. Ficou evidente para os autores desta pesquisa que o currículo sofre transformações, tendo em vista os interesses e as disputas de cada época, que influenciam as decisões que cada profissional da educação precisa tomar em sua atividade profissional.

\section{CONSIDERAÇÕES FINAIS}

Com este trabalho, pretendemos estabelecer uma compreensão sobre o papel da Física, enquanto área de conhecimento e consequentemente enquanto disciplina escolar, no ensino de Ciências dos anos iniciais da educação básica. A motivação para este trabalho surgiu especialmente a partir de questionamentos com relação a como a educação científica vem contribuindo para a formação das crianças que estão neste nível de ensino, no sentido de terem acesso aos conhecimentos de todas as áreas das Ciências Naturais. Ao destacarmos trabalhos que evidenciam que a Física tem sido abordada de maneira insuficiente nas séries iniciais, na medida em que corroboram com a percepção de que em geral os docentes, pedagogos e pedagogas, tendem a priorizar certos conteúdos, em especial da Biologia, buscamos trazer para a discussão o problema do ensino de ciências na formação inicial de docentes no curso de Pedagogia.

A partir da análise dos documentos, percebeu-se que conhecimentos da Física estão presentes explicitamente nos três documentos curriculares, objetos deste estudo, que vem norteando a atividade docente dos professores de Curitiba dos últimos trinta anos. Ou seja, a Física deve ser inserida no ensino de Ciências desde os anos iniciais da educação básica, porém a sua abordagem não é garantida, como aponta Rodrigues e Teixeira (2011). Embora possa parecer uma questão periférica às discussões curriculares, a questão da formação inicial de docentes para esta etapa torna-se uma questão central na medida em que o ensino de Física nas séries iniciais vem sendo sistematicamente negligenciado por falta de preparo dos docentes na educação científica. Ou seja, se não houver um esforço para implementar mudanças na formação científica de pedagogos e pedagogas, o ensino da Física previsto nos documentos curriculares nunca será efetivado.

A formação inicial de docentes constitui-se, admitimos, em uma dimensão complexa e que demanda ponderações. Cada instituição de ensino superior, 
levando em conta as particularidades e especificidades de seu contexto, estabelece o perfil do profissional em pedagogia que deve formar para o mercado de trabalho, o que guia seus processos de organização do processo formativo. Contudo, há que se observar dentre os aspectos a serem considerados nesta organização, que os documentos curriculares que dão as diretrizes da atividade docente para a educação básica se constitui em um dos pilares que precisam ser observados pelas instituições que ofertam cursos de Pedagogia. Em outras palavras, a formação de pedagogos e pedagogas precisa levar em conta a demanda de ensino para os anos iniciais proposta no âmbito do currículo.

Sendo assim, o ensino de Ciências constitui-se em uma das necessidades formativas para estudantes da licenciatura em Pedagogia, tanto quanto as demais áreas de conhecimento. Documentos curriculares de diferentes momentos históricos apontam a Ciência como parte integrante dos conhecimentos que precisam ser levados para os anos iniciais, e assim deve-se garantir que os profissionais formados para esta atividade tenham condições de abordar os conhecimentos científicos. Na análise empreendida no trabalho que resultou neste artigo, buscamos mostrar este aspecto, a fim de reforçar a defesa de que o ensino de Ciência precisa ser fortalecido, em especial no sentido de proporcionar aos futuros professores o embasamento necessário para abordar não só a dimensão biológica da educação científica, mas que leve em conta conhecimentos de todas as componentes curriculares das Ciências da Natureza, dentre elas a Física.

Defendemos que é preciso superar a ideia atual de que não se ensina Física nas séries inicias porque é difícil e inacessível às crianças nesta etapa de ensino. A Física é, enquanto uma das Ciências da Natureza, essencial para o estabelecimento de uma compreensão mais ampla dos diversos aspectos da natureza em si. Certamente não estamos falando da Física que se aborda tradicionalmente no Ensino Médio, focada em treinamento de resolução de exercícios matemáticos, mas na Física em sua dimensão conceitual, que uma vez que o profissional licenciado em Pedagogia tenha passado por uma formação adequada em relação ao ensino de Ciências, terá condições de planejar e concretizar situações didáticas que oferecem às crianças uma educação científica condizente com seus objetivos. 


\title{
Physics in the early years of basic education: an analysis of the curricular documents adopted by Curitiba/PR school system
}

\begin{abstract}
This paper presents a study about physics contents present in curricular documents of the early years of Elementary School. The goal is to address the issue of the insertion of Physics within the scope of the subject related to the Natural Sciences for this education level, considering the implications for the teaching organization and for the pre-service teacher training. This is a documentary research, in which the documents to be analyzed correspond to the curricular texts adopted by the Curitiba / PR municipal school system in the last three decades: the Basic Curriculum for the Public School of the State of Paraná (1990), the National Curriculum Parameters - from first to fourth grade (1997) and the Curitiba Elementary School Curriculum (2016). For the data constitution, the Discursive Textual Analysis methodology was used and, from the process of information fragmentation, the following analysis categories were constructed: 1) Physics contents indicated for the initial years; 2) knowledge of the Natural Sciences that refer to Physics indicated for the initial years and 3) broad themes that can be linked to knowledge of Physics in the initial years. As a result, it was noticed that Physics knowledge is explicitly present in all documents analyzed, but over time the curriculum guidelines come to incorporate methodological aspects in which the contents of physics are articulated with science teaching themes, as well as current scientific and technological topics and their relationships in the social context. These results show that Physics is an important dimension for the introduction to the Natural Sciences in the early grades, and needs to be approached together with the knowledge of the other areas of the Natural Sciences. This implies that initial education in pedagogy undergraduate courses must ensure that the future teacher, who will work in the early years of elementary school, has access to appropriate scientific training during undergraduate education, which will allow the articulation of Physics, Chemistry and Biology, without favoring one area of knowledge over others, something that researches have been pointing to be a recurring reality in school contexts.
\end{abstract}

KEYWORDS: Science education. First grades. Physics. Curriculum. Elementary School. 


\section{AGRADECIMENTOS}

Agradecemos à profa Marina de Lurdes Machado, pela contribuição com informações históricas sobre o processo de construção do currículo paranaense.

\section{REFERÊNCIAS}

BRASIL. Secretaria de Educação Fundamental. Parâmetros curriculares nacionais: ciências naturais. Ensino de primeira à quarta série. Volume IV. Brasília: MEC/SEF, 1997.

CAMPOS, R. S. P.; CAMPOS, L. M. L. A formação do professor de ciências para os anos iniciais do Ensino Fundamental e a compreensão de saberes científicos. Amazônia: Revista de Educação em Ciências e Matemática, v. 13, n. 25, p. 135146, Jul-Dez 2016.

CARVALHO, A. M. P. Ciências no ensino fundamental. Cadernos de Pesquisa da Fundação Carlos Chagas. № 101, p. 152 -168, Julho de 1997.

CHASSOT, A. Ensino de Ciências no começo da segunda metade do século da tecnologia. In: LOPES, A. C.; MACEDO, E. (orgs.) Currículo de ciências em debate. Campinas: Papirus, 2004.

CURITIBA. Secretaria Municipal de Educação. Currículo Fundamental de Curitiba: Ciências da Natureza. Volume IV, 2016.

GESSER, V. A evolução histórica do currículo: dos primórdios à atualidade. Revista Contrapontos. Ano 2, n. 4, Itajaí, jan-abr 2002.

MAGALHÃES JR, C. A. O.; PIETROCOLA, M. P. O. Formação dos Professores de Ciências Para o Ensino Fundamental. In: Anais do XVI Simpósio Nacional de Ensino de Física. Rio de Janeiro, 2005.

MORAES, R; GALIAZZI, M. C. Análise Textual Discursiva. Ijuí: Editora Unijuí, 2011.

MOZENA, E. R.; OSTERMANN, F. A Pesquisa em Ensino de Física nas Séries Iniciais do Ensino Fundamental: uma Revisão de Literatura em Artigos Recentes de Periódicos Nacionais "qualis A". In: Anais do XI Encontro de Pesquisa em Ensino de Física. Curitiba, 2008.

LOPES, A. C.; MACEDO, E. (orgs.) Currículo de ciências em debate. Campinas: Papirus, 2004.

PARANÁ. Secretaria de Estado da Educação. Currículo Básico para a Escola Pública do Estado do Paraná. Curitiba: SEED, 1990.

RODRIGUES, M. A.; TEIXEIRA, F. M. O ensino de física nas séries iniciais do Ensino Fundamental na Rede Municipal de Ensino do Recife segundo os seus docentes. Revista Brasileira de Ensino de Física, v. 33, n. 4, p. 4401, 2011. teóricas e metodológicas. Revista Brasileira de História \& Ciências Sociais RBHCS, v. 1, n. 1, 2009. 
SILVA, T. T. Documentos de identidade: uma introdução às teorias do currículo. 3a Ed. Belo Horizonte: Autêntica, 2010.

Recebido: 23 ago. 2018

Aprovado: 28 out. 2019

DOI: 10.3895/actio.v4n3.10517

Como citar:

Roehrig, S. A. G.; Santos, M. V. F. A física nos anos iniciais da educação básica: uma análise dos documentos curriculares adotados pela rede municipal de Curitiba/PR. ACTIO, Curitiba, v. 4, n. 3, p. 292

308, set./dez. 2019. Disponível em: <https://periodicos.utfpr.edu.br/actio>. Acesso em: XXX

Correspondência:

Silmara Alessi Guebur Roehrig

Av. Sete de Setembro, 3165 (Departamento Acadêmico de Física) - Rebouças, Curitiba - PR.

Direito autoral: Este artigo está licenciado sob os termos da Licença Creative Commons-Atribuição 4.0

Internacional.

(c) (1) 